\title{
Improving science through online commentary
}

\author{
The Internet offers a timely opportunity to widen, and reduce delays in, scientific debate.
}

Sir — Progress in science depends on public debate and criticism of ideas. Unfortunately, debate is largely restricted to four domains: conferences, private conversations, journal clubs and peer-reviewed publications. The first three channels tend to be too private and ephemeral to help the community at large. Publication in journals runs on a timescale of months and, unless people bring new data, they are lucky to be allowed into the debate at all. This slow communication hampers progress. Most people do not know other scientists' views on published manuscripts. When a new paper appears, readers often spot logical flaws, experimental weaknesses, questionable assumptions or alternative interpretations. Yet individual criticisms may not be considered important enough to warrant publication. Even major criticisms are unlikely to appear until months or years later, and are often overlooked in the haystacks of the literature. Scientists even miss official retractions, continuing to cite withdrawn data accidentally.

We propose a simple solution. Each record in publication databases (such as the US National Library of Medicine's PubMed) should have a link for adding scientific commentary: essentially the electronic version of a Post-it note. The submitter of a comment would be required to provide his or her name, e-mail address, a short communication and potentially a password (for later editing or deletion). Insights, criticism, replications and nonreplications could be posted.

The benefits of this system would include: immediate free and open debate of scientific ideas and results; easy dissemination of non-replications and negative results; a reduction in wild-goose chases by researchers unaware of others' insights into a published paper; and posting of links to subsequent papers that provide important verifications or contradictions.

The attachment of commentary to databases has been successful in other areas. Users can add 'Post-em' links to a public-domain genealogy database, the Social Security Death Index (http://ssdi. genealogy.rootsweb.com/cgi-bin/ssdi.cgi). Readers attach reviews to books in Amazon.com's database.

Since we desire our proposal to be practical and inexpensive, there would be no human gatekeeper. To avoid abuse, we suggest that unhelpful or libellous notes could be reported to a removal moderator, who would decide whether to eliminate them. To prevent milder forms of abuse, Amazon.com asks: "Was this review helpful to you?" Answers are tallied to give a sense of how the community values the comment. Automatic advertisement posting can be prevented by a requirement to key in a text code readable only by humans.

Given the importance of peer-reviewed publications to their careers (see P. Lawrence Nature 422, 259-261; 2003), will researchers freely provide their insights without any career benefit? They already do. During the peer-review process, most scientists spend a lot of time providing insights to a very few people. Posting a note would benefit the whole community and take very little time.

A handful of journals have begun experiments in 'open' peer review online operates on a journal-by-journal basis, whereas our proposed post-publication commentary process should be centralized (see T. Gura Nature 416, 258; 2002). This

and independent of the journal of publication. For example, the commentaries on biological and medical papers should be stored in a single database under the freeaccess, disinterested aegis of the US National Library of Medicine.

We believe that this simple, practical idea could substantially speed the practice and progress of science. We address further issues and welcome feedback at www.cnl. salk.edu/ eagleman/postit.

David M. Eagleman ${ }^{\star}$, Alex O. Holcombe $\dagger$

${ }^{\star}$ Computational Neurobiology Laboratory,

The Salk Institute for Biological Studies,

La Jolla, California 92037, USA

eagleman@salk.edu

$\dagger$ Department of Psychology, University of

California, San Diego, La Jolla,

California 92093, USA

holcombe@post.harvard.edu

\section{Oil and war: we had the warning $\mathbf{3 0}$ years ago}

Sir — The other night, I was looking for an article in Nature from 1973 when the volume fell open to an editorial, "What future for energy?" (Nature 242, 357-358; 1973). I quote the closing part: “...there is every prospect that the immediate problems of energy scarcity could be brought within control in the measurable future. Fuller use of the price mechanism and more resolute decision-making by the Federal Government are urgently necessary, but could make the immediate "crisis" go away. By the 1990s, however, the United States will have more serious problems to contend with. It now seems clear that the annual import bill for petroleum products is bound to increase steadily, and the chances are that even by 1980 , the United States will be spending $\$ 20,000$ million a year (or more if there are further devaluations of the dollar) on imported crude petroleum. Numerically, this expenditure is not insupportable, but there are political snags. The Administration is, for example, alarmed at the prospect that so much cash will find its way into the hands of Arab states which have no automatic sympathy with United States policy in the Middle East — rather the reverse - and which could use their holdings of the large quantities of dollars as a way of manipulating the international currency market. But even this is not an entirely unwelcome prospect, for at the very least it will create a climate in which some lasting political settlement in the Middle East will seem to everybody desirable. And here, luckily, there is plenty of time in which the United States can prepare the ground for a lasting policy. To be sure, in the meantime it will be prudent also to pursue as vigorously as possible the technical means by which other sources of energy might be exploited, and no doubt there is much to be done to make use of geothermal steam and solar energy. But the problem of the 1990s is already definable and is largely political in character. It is to be hoped that the United States will not let that blow up into a crisis for lack of resolution in the next few years."

Thirty years later, the Israeli-Palestinian situation could not be worse. War in Iraq has cost thousands of lives during the past few weeks. Republicans in the US Congress recently fell just two votes short of passing legislation that would allow oilfields to be Refuge on Alaska's North Slope, and the president vowed to redouble efforts to open the refuge to drilling. There have been no significant investments in new energy technologies, and no breakthroughs in technologies or new sources.

The perspective offered by your stunning, telling editorial in 1973 provides some important, albeit expensive, lessons. Michael D. Jennings

Donald Bren School of Environmental Science and Management, University of California, Santa Barbara, and Department of Fish and Wildlife Resources, University of Idaho, PO Box 441136, Moscow, Idaho 83844-1136, USA

The author of the editorial was John Maddox, then Editor of Nature Editor, Correspondence drilled in the Arctic National Wildlife 